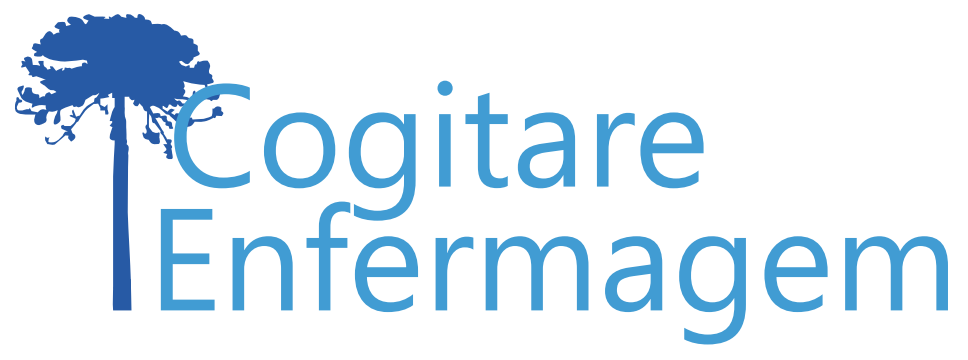

\title{
INFORMAÇÕES EPIDEMIOLÓGICAS SOBRE A COVID-19: INFLUÊNCIA DA CIBERCULTURA NO ENGAJAMENTO POPULAR ÀS MEDIDAS DE CONTROLE
}

Elaine Cristina Carvalho Moura1, Violeta Lopez ${ }^{2}$, Samuel Freitas Soares ${ }^{3}$

\section{RESUMO}

Objetivo: analisar a comunicação de informações epidemiológicas para a adesão da população às medidas de controle, na perspectiva de Pierre Levy e Littlejohn.

Desenvolvimento: a reflexão contextualiza a influência das informações online, mídias sociais e televisão na construção da cibercultura brasileira. Foi analisada a importância de informações epidemiológicas detalhadas, incluindo deficiências no rastreamento de contatos e na expansão da cobertura dos testes, para o efetivo engajamento comunitário.

Conclusão: a comunicação em massa contribui efetivamente para nova inteligência coletiva em ciberespaços que caracterizam a cibercultura brasileira. Quanto mais transparentes forem as informações oficiais, maior adesão e apoio das populações no controle da pandemia.

DESCRITORES: Covid-19; Vigilância Epidemiológica; Comunicação; Enfermagem; Saúde Pública.

COMO REFERENCIAR ESTE ARTIGO:

Moura ECC, Lopez V, Soares SF. Informações epidemiológicas sobre a Covid-19: influência da cibercultura no engajamento popular às medidas de controle. Cogitare enferm. [Internet]. 2020 [acesso em "colocar data de acesso, dia, mês abreviado e ano"]; 25. Disponível em: http://dx.doi.org/10.5380/ce.v25i0.74566.

${ }^{1}$ Enfermeira. Doutora em Enfermagem. Docente de Enfermagem da Universidade Federal do Piauí. Teresina, PI, Brasil. 9 ${ }^{2}$ Enfermeira. Doutora em Enfermagem. Chair Professor, School of Nursing, Hubei University of Medicine, China.

${ }^{3}$ Enfermeira. Mestre em Enfermagem. Gerente de Enfermagem da Neoclínica; Programa de Pós graduação em Enfermagem da Universidade Federal do Piaui. Teresina, PI, Brasil. 9 


\title{
EPIDEMIOLOGICAL INFORMATION ON COVID-19: INFLUENCE OF CYBERCULTURE ON POPULAR ENGAGEMENT TO CONTROL MEASURES
}

\begin{abstract}
Objective: To analyze the communication of epidemiological information for the population's adherence to control measures, from the perspective of Pierre Levy and Littlejohn.

Development: Reflection contextualizes the influence of online information, social media, and television in the construction of the Brazilian cyberculture. The importance of detailed epidemiological information was analyzed for effective community engagement, including deficiencies in tracking contacts and expanding test coverage.

Conclusion: Mass communication contributes effectively to new collective intelligence in cyberspaces that characterize the Brazilian cyberculture. The more transparent the official information, the greater the adherence and support of the populations in controlling the pandemic.
\end{abstract}

DESCRIPTORS: Covid-19; Epidemiological Surveillance; Communication; Nursing; Public Health.

\section{INFORMACIONES EPIDEMIOLÓGICAS SOBRE COVID-19: INFLUENCIA DE LA CIBERCULTURA EN EL ACATAMIENTO DE LA POBLACIÓN A LAS MEDIDAS DE CONTROL}

\begin{abstract}
RESUMEN:
Objetivo: analizar la comunicación de las informaciones epidemiológicas para el acatamiento de la población a las medidas de control, desde la perspectiva de Pierre Levy y Littlejohn.

Desarrollo: la reflexión contextualiza la influencia que ejercen las informaciones en línea, en los medios sociales, y en la televisión en la construcción de la cíbercultura brasileña. Se analizó la importancia de informaciones epidemiológicas detalladas, incluidas deficiencias en el rastreo de contactos y en la expansión de la cobertura de las pruebas, a fin de lograr un efectivo acatamiento comunitario.

Conclusión: la comunicación masiva contribuye de manera eficaz a desarrollar una nueva inteligencia colectiva en los ciberespacios que caracterizan a la cibercultura brasileña. Cuanto más transparente sea la información oficial, mayor será el acatamiento y el apoyo de las poblaciones en cuanto al control de la pandemia.
\end{abstract}

DESCRIPTORES: Covid-19; Vigilancia Epidemiológica; Comunicación; Enfermería; Salud Pública. 
As epidemias relacionadas à Síndrome Respiratória Aguda Grave (SARS), desde 2002, tem tido enfoque global. Atualmente, a Covid-19, causada pelo coronavírus SARS-CoV-2, tem revivido impactos socio-econômicos-culturais experimentados pela gripe espanhola de 1918 e preocupado quanto à morbimortalidade(1). A Organização Mundial de Saúde (OMS) declarou em janeiro de 2020 o surto por Covid-19 uma Emergência de Saúde Pública de Interesse Internacional. Pelo menos 216 dos países do mundo têm empreendido esforços no controle da pandemia(2).

A vigilância epidemiológica eficaz no controle do SARS-CoV-2 inclui detecção, diagnóstico, tratamento, quarentena precoces e rigoroso rastreamento de contatos para bloquear a transmissão exponencial do vírus (3-4). $^{(3)}$ Mais de 90 equipes de pesquisa internacionais estão sendo conduzidas no desenvolvimento de vacinas, e pelo menos seis grupos já começaram a injetar formulações em voluntários, a nível de ensaios de segurança(5-6).

A OMS atualiza as recomendações ao público em geral com base nas evidências cientificas. As principais medidas envolvem distanciamento social, higiene das mãos, rosto e respiratória(2).

A vigilância epidemiológica na era da comunicação em contexto de massa e digital tem enfrentado desafios, especialmente nos processos de comunicação, visando ações de controle da pandemia nos diversos países ${ }^{(7-8)}$. As mensagens públicas decorrentes da comunicação em massa e emitidas por meio da mídia, representadas, nesse estudo, pela televisão e material impresso de um lado e pela internet, dividida em disposição online geral e mídias-sociais, do outro, envolvem a inteligência coletiva da humanidade, pautada na globalização e interligação do espaço para exponencial número de receptores ${ }^{(7)}$.

O mecanismo de ação da Covid-19 tem sido conhecido e atualizado na prática cotidiana profissional de enfretamento da doença, gerando opiniões plurais dos especialistas e evidências científicas preliminares. Considerando a ausência de tratamento específico e vacina eficazes, interromper a transmissão continua sendo a melhor defesa contra a doença ${ }^{(2)}$.

De fato, o controle da velocidade de transmissão esbarra nas condições econômicoestruturais de cada país, aliadas ao gerenciamento dos sistemas de saúde pública, medidas epidemiológicas, condições sociais e comportamentais, que inclusive inviabilizam uma abordagem única (2). Assim, a comunicação eficaz de dados confiáveis é fundamental para a adesão das medidas de responsabilidade social nas coletividades.

No Brasil, a complexidade e alcance da comunicação em mídia tem sido preocupante. Pesquisas revelam que os brasileiros (62\%) são os que mais acreditam em notícias falsas; tem predisposição a participar de grupos públicos de WhatsApp com desconhecidos, inclusive partidários; e $58 \%$ dos entrevistados costumam compartilhar notícias em que acreditam ${ }^{(9-11)}$. Esse cenário é propício a ruídos e alguma manipulação comportamental, que certamente afetam a comunicação em tempos de pandemia.

A presente reflexão tem como objetivo analisar a comunicação de informações epidemiológicas sobre a pandemia da Covid-19 no Brasil, a fim de favorecer as bases necessárias para a adesão da população às medidas de controle. 
online, mídias sociais e televisão na construção da cibercultura brasileira(9-11). Foram destacadas informações epidemiológicas que favorecem o entendimento da comunidade quanto às medidas coletivas de enfrentamento ao Covid-19. A análise consta de concepções sobre comunicação de Pierre Levy e Littlejohn ${ }^{(7-8)}$.

As tecnologias digitais de informação em ciberespaços tem superado a comunicação em massa veiculada em televisão e impressa ${ }^{(7-8,10)}$. Um panorama comparativo do ciberespaço no Brasil entre 2013 e 2019 mostrou que a consulta de informações por mídia online se manteve estável (90\%/87\%), porém por mídias sociais apresentou amplo crescimento de $47 \%$ para $64 \%$. A televisão obteve leve declínio (75\%/73\%), enquanto a mídia impressa reduziu $50 \%$ do consumo em $2019^{(10)}$.

Assim, as mídias sociais, mídia-online e televisão são as mais responsáveis pelo consumo de notícias/informações no Brasil. O nível de confiança dos brasileiros nas notícias em geral consumidas é de $48 \%$. Das notícias que leem, a confiança é de $59 \%$; das que pesquisam $47 \%$. Porém, nas notícias lidas em mídias sociais, a confiança diminui para $31 \%(9,10)$.

Os dados apresentados podem caracterizar a cibercultura da população brasileira nos diversos âmbitos da vida coletiva, sobretudo aliado aos $62 \%$ que acreditam nas notícias antes de verificar a veracidade e aos $58 \%$ que as compartilham nas mídias sociais. Esse cenário se reflete no enfrentamento da crise sanitária da Covid-19 no Brasil, em meio a uma crise política e econômica pré-existente ${ }^{(9)}$.

Dentre os brasileiros entrevistados, $58 \%$ se preocupam com omissão de informação/ desinformação, por referirem que um cidadão brasileiro médio não identificaria uma notícia falsa(10). Essa preocupação teve acréscimo de 11 pontos percentuais entre 2013 e 2019, devido ao uso das mídias sociais nas eleições presidenciais de 2018, especialmente por meio do WhatsApp, que representa $53 \%$ da fonte de notícias e $84 \%$ da fonte de informações em geral dos brasileiros entrevistados ${ }^{(10)}$. Esse dado pode refletir na adesão da população ao controle epidemiológico da Covid-19, devido à credibilidade das autoridades competentes.

Uma pesquisa no banco de dados do Ministério da Saúde (MS) entre 29 de janeiro e 31 de março de 2020 identificou 70 notícias falsas sobre o Covid-19, sendo 40 relacionadas aos discursos de autoridades sanitárias, 17 à terapêutica, nove sobre medidas de prevenção, duas relativas ao prognóstico da doença e duas sobre vacinação(12).

A comunicação integra inúmeros elementos inseridos nos processos de significação, codificação, pensamento, informação e persuasão nas sociedades ${ }^{(8)}$. Todos os contextos e processos de comunicação têm sido exigidos no enfrentamento da pandemia. $O$ contexto de comunicação em massa, no entanto, especialmente a cultura instalada no ciberespaço, quando alimentada por informações não confiáveis, pode gerar alcance exponencial e caótico ${ }^{(4,7)}$, comparável, inclusive, ao processo de transmissão da Covid-19.

No Brasil, o enfrentamento da Covid-19 tem sido turbulento entre as autoridades políticas e sanitárias, havendo constantes divergências de informações oficiais, evidenciando e até condicionando a população a recorrer aos meios de comunicação em massa e digital no processo de entendimento, controle e monitoramento dos eventos relacionados à pandemia.

O MS informa diariamente dados oficiais sobre casos confirmados, recuperados, novos e óbitos fornecidos pelas Secretárias de Saúde brasileiras. Aponta como limitações das informações a diversidade dos municípios brasileiros e a escassez do teste padrão ouro para Covid-19, a RT-PCR (Reação em cadeia da polimerase) e insumos relacionados ${ }^{(13)}$. Ao que parece, o foco da investigação epidemiológica ocorre pelas hospitalizações e complicações para SRAG e doenças respiratórias severas.

A comunicação eficaz, de fato, esbarra na capacidade dos sistemas de vigilância, que devem ser geograficamente abrangentes e incluir todas as pessoas e comunidades 
em risco para romper as cadeias de transmissão da Covid-19. O rastreamento de contato é uma etapa rigorosa da vigilância para identificação, avaliação e gerenciamento de pessoas que foram expostas a casos confirmados, exigindo acompanhamento diário do contato por 14 dias, a partir do último ponto de exposição. Assim, é essencial garantir equipes de rastreadores e supervisores de contato treinadas; suporte logístico para o contato; e sistema de gerenciamento dos dados coletados, considerando, sobretudo, planejamento cuidadoso para o efetivo engajamento comunitário(14).

O rastreamento preconizado de contatos permite avaliar as medidas de restrição e, inclusive, implantar soluções digitais de controle, a exemplo de Cingapura, que disponibilizou - TraceTogether e o SafeEntry. O primeiro identifica via Bluetooth um contato de até 2 metros de distância entre dois usuários, e subsidia rastreadores na rápida identificação de contatos. O SafeEntry é um sistema nacional de check-in digital que registra a entrada e saída de indivíduos em um local. O sistema captura detalhes, por meio de código QR, que permitem localizar contatos próximos de casos infectados, acelerando o rastreamento e impedindo a formação de novos clusters naquele local. O TraceTogether é instalado nos celulares e o SafeEntry tem sido implantado em locais com maior risco de contato não transitório, como shoppings e supermercados desde abril de $2020^{(15)}$.

Outro aspecto que merece destaque nesta análise é a avaliação de alta dos casos recuperados de Covid-19, na qual são preconizados pelo menos dois resultados-testeCovid-19 negativos com pelo menos $24 \mathrm{~h}$ de intervalo e, para casos leves, suspensão de medidas de isolamento a partir dos seguintes critérios: desaparecimento de febre na ausência de antitérmicos, melhora gradual de sinais e sintomas clínicos, e resultados negativos para testes moleculares ${ }^{(16,17)}$. No Brasil, os casos recuperados têm sido estimados por um cálculo composto baseado nos registros oficiais de casos e óbitos com confirmação de Covid-19(13).

Qualquer perturbação no sentido da mensagem no processo fonte-canal-receptor durante a transmissão da informação gera ruído ${ }^{(8)}$. Fatos ruidosos nas informações epidemiológicas oficiais brasileiras ocorreram em 04 de junho de 2020, quando o layout do Painel Corona Vírus foi temporariamente interrompido e, posteriormente, modificado. Essa alteração não prosperou. A intenção era fornecer informações sobre óbitos apenas do dia, com a alegação de que as informações cumulativas passadas pelas Secretarias Estaduais precisavam ser conferidas. Esses fatos geram barreira efetiva para comunicação eficaz em todos os contextos e processos de comunicação, desde intrapessoal, interpessoal, grupos, massa ao digital.

Numa análise global, países asiáticos como Cingapura oferecem informações acessíveis, constando de número de casos novos (incluindo os importados, na comunidade e hospitalares); rastreio de contatos constando os pendentes; fatalidades; total de altas hospitalares; total de altas diárias; e total de casos confirmados e ativos. Para evitar deturpações dessas informações, o MS diariamente esclarece quaisquer notícias de conteúdo equivocado relativas à epidemia ${ }^{(15)}$. O Governo tem assegurado, ainda, a partir das reservas nacionais, pacotes de combate ao impacto econômico da pandemia, visando manutenção de empregos e empresas, entre outros ${ }^{(18)}$.

Comparando dados de 20 de maio de 2020 entre Brasil e Cingapura, em que os dois países tropicais apresentavam número de casos totais similares, Cingapura registrava 23 fatalidades, ao passo que o Brasil registrava 18.859(13,15).

O Brasil tem penetração de internet de até $71 \%$ para comunicação digital e em massa ${ }^{(10)}$. Em tempos de acirrada polarização política, os efeitos da comunicação oficial confiável seriam, sobremaneira, válidos para aumentar o apoio e discernimento comunitário. A sociedade esclarecida pode exigir das autoridades competentes medidas de suporte aos serviços de vigilância e saúde, e ainda reivindicar pacotes econômicos viáveis.

O ciberespaço na era digital prepara o emissor que visualiza a informação e reage a ela, muitas vezes imediatamente, de modo que as etapas de combinação entre conhecimentos e habilidades podem ser desconsideradas, inclusive em assuntos técnicos, 
gerando atitudes às vezes precipitadas diante da informação, resultando em interação de saberes, numa nova inteligência social ${ }^{(7,19)}$. Esse mecanismo acontece seja por fonte confiável ou não.

As dimensões continentais do Brasil e as diferenças entre estados, capitais e municípios exigem análises dos recursos constitucionais, climáticos, ambientais, estruturais, infraestruturais e das lideranças muito diversas. É no engajamento das comunidades que pode emergir o grau de senso coletivo do seu povo, independente até mesmo de graus de instrução e da diversidade regional. Desse modo, as fontes oficiais de informações confiáveis favorecem a sinergia coletiva necessária no atual enfrentamento de uma doença que não negocia com a omissão de informações, enquanto existir amplo ciberespaço democrático.

\section{CONCLUSÃO}

A comunicação eficaz de informações epidemiológicas sobre a pandemia da Covid-19 no Brasil polarizado gera uma nova inteligência coletiva nos ciberespaços, caracterizando a cibercultura brasileira. Toda a população está suscetível ao SARS-Cov2. Assim, quanto mais transparentes em detalhes forem as informações oficiais, haverá maior adesão e apoio das populações às condições de controle; mais consciência dos deveres das autoridades competentes, dos direitos coletivos e individuais para gestão eficaz da pandemia.

\section{REFERÊNCIAS}

1. Harari YN. Homo Deus: a brief history of tomorrow. London: Penguin Random House; 2015.

2. World Health Organization (WHO). Coronavirus disease (COVID-19) pandemic. [Internet]. Geneva: WHO; 2020 [acesso em 23 mar 2020]. Disponível em: https://www.who.int/emergencies/diseases/novelcoronavirus-2019.

3. Zu ZY, Jiang MD, Xu PP, Chen W, Ni QQ, Lu GM, et al. Coronavirus Disease 2019 (COVID-19): a perspective from China. Radiology [Internet]. 2020 [acesso em 21 de fev 2020]. Disponível em: https:// doi.org/10.1148/radiol.2020200490.

4. World Health Organization (WHO). Surveillance strategies for COVID-19 human infection (Interim Guidance) [Internet]. Geneva: WHO; 2020 [acesso em 20 maio 2020]. Disponível em: https://www.who.int/ publications-detail/critical-preparedness-readiness-and-response-actions-for-covid-19.

5. Callaway E. The race for Coronavirus vaccine: a graphical guide. Nature. [Internet]. 2020 [acesso em 30 abr 2020]. Disponível em: https://doi.org/10.1038/d41586-020-01221-y.

6. Cohen J. COVID-19 shot protects monkeys: vaccine from chinese firm uses old-fashioned "killed" virus. Science. [Internet]. 2020 [acesso em 20 maio 2020]; 368(6490). Disponível em: https://doi.org/10.1126/ science.368.6490.456.

7. Lévy P. Cibercultura. 3. ed. São Paulo: Editora 34; 2011.

8. Littejonh SW, Foss KA. Theories of human communication. 10. ed. Long Grove: Waveland; 2011.

9. Ipsos Public Affairs. Fake news, filter bubbles, post-truth and trust: a study across 27 countries.

[Internet] Ipsos; 2018 [acesso em 16 jun 2020]. Disponível em: https://www.ipsos.com/en/fake-news-filterbubbles-and-post-truth-are-other-peoples-problems. 
10. Newman N, Fletcher R, Kalogeropoulos A, Nielsen R K. Reuters Institute Digital News Report 2019. University of Oxford: Reuters Institute for Journalism; 2019.

11. Bursztyn VS, Birnbaum L. Thousands of small, constant rallies: a large-scale analysis of partisan WhatsApp groups. ASONAM'19 [Internet]. 2019 [acesso em 20 maio 2020]. Disponível em: https://doi. org/10.1145/3341161.3342905.

12. Neto M, Gomes T de O, Porto FR, Rafael R de MR, Fonseca MHS, Nascimento J. Fake news no cenário da pandemia de Covid-19. Cogitare enferm. [Internet]. 2020 [acesso em 22 maio 2020]; 25. Disponível em: http://dx.doi.org/10.5380/ce.v25i0.72627.

13. Ministério da Saúde (BR). Coronavirus/Brasil. Covid19 - Painel Coronavirus [Internet]. Brasília: 2020 [acesso em 28 maio 2020]. Disponível em: https://covid.saude.gov.br/.

14. World Health Organization (WHO). Contact tracing in the context of COVID-19 (Interim guidance) [Internet]. Geneva: WHO; 2020 [acesso em 20 maio 2020]. Disponível em: https://www.who.int/ publications/i/item/contact-tracing-in-the-context-of-covid-19.

15. Ministry of Health Singapore. Updates on Covid-19 (Coronavirus Disease 2019) local situation. [Internet]. Singapore: MOH; 2020 [acesso em 28 maio 2020]. Disponível em https://www.moh.gov.sg/ covid-19.

16. Centers For Disease Control and Prevention (CDC). Interim infection prevention and control recommendations for patients with known or patients under investigation for 2019 novel Coronavirus (2019-nCoV) in a healthcare setting. [Internet]. 2020 [acesso em 16 jun 2020]. Disponível em: https://www. cdc.gov/coronavirus/2019-ncov/hcp/infection-control.html.

17. World Health Organization (WHO). Clinical management of severe acute respiratory infection (SARI) when COVID-19 disease is suspected (Interim guidance) [Internet]. Geneva: WHO; 2020 [acesso em 20 maio 2020]. Disponível em: https://apps.who.int/iris/bitstream/handle/10665/331446/WHO-2019-nCoVclinical-2020.4-eng.pdf? sequence=1\&isAllowed=y.

18. Baker JA. Fortitude budget: additional $\$ \$ 800$ million set aside for COVID-19 Support Grant; S\$100 one-off utilities credit. [Internet]. 2020 [acesso em 26 maio 2020]. Disponível em https://www. channelnewsasia.com/news/singapore/fortitude-budget-utilities-credit-support-grant-12770402.

19. Moura ECC. Ensino-aprendizagem de enfermagem em simulação clínica: desenvolvendo competência profissional para prevenção de úlceras por pressão [tese]. Ribeirão Preto (SP): Universidade de São Paulo. Escola de Enfermagem de Ribeirão Preto; 2013. 
Recebido: 18/06/2020

Finalizado: 10/07/2020

Editora associada: Luciana Puchalski Kalinke

Autor Correspondente:

Elaine Cristina Carvalho Moura

Universidade Federal do Piauí

Av. Ininga, sn - 64000 - Teresina, PI, Brasil

E-mail: elaineccmoura@outlook.com

Contribuição dos autores:

Contribuições substanciais para a concepção ou desenho do estudo; ou a aquisição, análise ou interpretação de dados do estudo - ECCM

Aprovação da versão final do estudo a ser publicado - VL, SFS

\section{(c) (4)}

Este obra está licenciado com uma Licença Creative Commons Atribuição 4.0 Internacional. 